\title{
The Social Skill Preferences Of Tax Professionals In CPA Firms: A FIRO-B Analysis
}

Michelle Bertolini, University of Hartford, USA Carl Borgia, Florida Atlantic University, USA Philip H. Siegel, James Hull College of Business, USA

\begin{abstract}
The social interaction preferences of tax professionals working in U.S. accounting firms are analyzed and compared with other public accounting firm personnel. Social skill preferences are analyzed using the FIRO-B methodology which has been widely validated and applied to accounting professionals. Considering the high cost of turnover and the nominal cost of using the FIRO-B instrument, it makes sense for businesses and educational institutions to use FIRO-B analysis as an aid in counseling, training, and assisting individuals entering the accounting profession. The findings of this study indicate that tax professionals have significantly higher social interaction preferences than other accounting professionals employed in public accounting. This makes sense in light of the demands put on tax accountants to work with a wide range of other professionals within, and external to, the firm.
\end{abstract}

Keywords: Tax Professionals, Employee Retention, Social Interaction Index, Social Skills Preferences, FIRO-B

\section{INTRODUCTION}

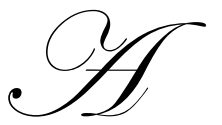

$\mathrm{s}$ the need for tax accountants increases, understanding the personality traits and social skills of the tax professional could assist companies and accounting firms in hiring, developing, and retaining those individuals whose profiles best match that of a tax professional (Anonymous 2008a; Anonymous 2008b). In the current international environment, tax issues are becoming more complex, and experienced tax professionals can assist firms to be more efficient and effective (Lassila and Smith 1997). The purpose of this study is to identify which personality traits and social skills tax professionals demonstrate using the Fundamental Relationship Orientation Behaviour (FIRO-B) methodology. This knowledge may be applied in both academic and professional circles.

Both academic and practitioner journals have published articles on the importance of retaining a qualified accounting and tax staff. For example, Kuesel and Ryan (2008) and Steadman (2008) review the costs and benefits of retaining qualified staff, and how to retain staff. Viator (2001) focuses on mentoring and its important role in retaining employees. And, Sheridan (1992) explores organizational culture, and how culture, and other firm attributes have an effect on length of retention. Thus, retention of accounting and tax staff is an important goal. This study hopes to determine the social interaction preferences of successful tax professionals as a way of advising individuals interested in working in this area.

The benefits of maintaining an adequate tax staff becomes particularly apparent when you consider the complexities inherent in tax practice (Anonymous 2008a; Anonymous 2008b). For example, tax professionals often require advance knowledge in such areas as international taxation, state and local taxes, and advanced-federal tax planning. They are in high demand, and turnover can be costly (Anonymous 2008c). High turnover requires additional effort on behalf of businesses to recruit qualified individuals, and to train and retain them (Anonymous 2008d). 
The comparison of these two groups should assist both accounting firms and potentially other types of companies to gain a better understanding of accounting professionals and. in particular, of the tax professionals on their staff. This understanding can help firms and companies better match the social preferences of staff to their particular practice area. It might also be helpful to universities in counselling students as they make their career decisions.

\section{SOCIAL SKILLS OF ACCOUNTING PROFESSIONALS}

Identifying social, psychological and emotional traits can assist companies to better understand what drives a person to perform or excel in a particular area. In addition, understanding the effects of personality characteristics and social skills is helpful because a mismatch of characteristics and skills could lead to poor job performance, dissatisfaction and potentially high turnover of employees and staff (Kleinman and Palmon 2000; Scarborough 1993). Research indicates the cost of turnover can be as high as $\$ 12,000$ per day (Anonymous $2008 \mathrm{~d}$ ).

Exploration of individual personality traits is firmly established in the accounting literature. Past studies suggest that within the accounting profession, certain personality characteristics and social skills lead to an individual's success (Siegel et al. 2001; Schloemer and Schloemer 1997; Satava 1996). Jacoby 1981 noted there are personality differences between tax and non-tax professionals within CPA firms. However, he did not explore the social interaction needs of these professionals. CPA and other firms can use the FIRO-B instrument and analysis to assist in hiring, employing and promoting tax professionals who best fit within the firm's organizational structure (Poznanski and Bline 1997; Pasewark and Strawser 1996; Ahadiat and Smith 1994; Dean et al. 1988).

Accounting literature does explore certain traits in tax professionals. Michaelsen and Nichols (1999) find that tax professionals who are confident, secure, introspective and familiar with tax issues are also the individuals who communicate a greater amount of useable knowledge to the client. Kahle and White (2004) examine initial belief and client preference bias in tax situations. They find that tax professionals' initial belief is revised by future evidence gathering, and this belief revision is greater when the evidence supports clients' preferred outcome. Cruz, Shafer and Strawser (2000) consider which ethical traits most heavily affect tax professionals' decision-making. These researchers find moral equity and contractualism had the greatest effect. In all of these cases, the authors are examining the reaction of tax professionals in certain situations, and not the differences in their personality or social skills.

Wheeler (2001) reports accounting professionals' personality types are consistent over time, firm and corporate size, and geographic location. He shows, however, that differences do exist in needs among accountants in varying settings. Therefore, tax professionals could have different behavioural characteristics based upon different work settings, but research has shown that their underlying personality types do not change much. The present study is directed at finding whether social skill interaction differences exist between tax professionals and other accounting professionals.

\section{FIRO-B AND SOCIAL INTERACTION PREFERENCES}

The concept of FIRO-B theory and the associated research was developed by Schutz (1958). Although the basic theory of FIRO-B is unchanged, the concept and instrument have undergone some modifications and expansions (Thompson and Schutz 2000; Schutz 1994, 1992).

The FIRO-B theory identifies three interpersonal needs; inclusion, control and affection that together measure the degree of need an individual has for social interaction using the Social Interaction Index (SII). Furthermore, these three needs are broken down into two sub-categories, expressed and wanted. The expressed subcategory measures an individual's desire to include, like, and control others. The wanted sub-category is the opposite and measures the individual's need for others to express their desire to include, like, and control them.

FIRO-B theory is based on the premise of an individual seeking to develop relationships with others. As part of this development of one's needs, the individual seeks relationships that contain the three interpersonal needs of inclusion, control and affection (Siegel et al. 2001; Thompson and Schutz 2000; Whetten and Cameron 1988). A recap of the various categories and their definition follows: 


\section{Inclusion}

Inclusion relates to a person's need for "interaction and belonging." People like to be social and participate in group activities. The degree of need to be included varies among individuals. Expressed inclusion occurs when an individual has a need to include others. Wanted inclusion occurs when an individual has a need to be included. At one end of the spectrum are those people who are extraverted (over-social). At the other end are those who are introverted (under-social).

\section{Affection}

Affection relates to a person's need for intimacy and friendship. Like inclusion, need varies in strength among individuals. Some people are very private and others are gregarious. Expressed affection occurs when an individual has a need to like others. Wanted affection occurs when an individual has a need to be liked.

\section{Control}

Control relates to a person's need to maintain a satisfactory balance of power and influence in relationships. Some people are dominant while others are subordinate. Expressed control occurs when an individual has a need to control others. Wanted control occurs when an individual has a need to be controlled.

The Social Interaction Index (SII) is a cumulative score of all three above components (Schutz 1966). Scores range from 0 to 9 for expressed and wanted sub-categories for each of the three interpersonal needs. The total SII score, therefore, will range from 0 to 54 . The higher the score, the higher the overall interpersonal need. In this study, the scores of tax professionals will be compared to the scores of other accounting professionals working for public accounting firms. Significant differences between these groups would indicate that a different set of social skills are required for tax than other accounting areas, and this information could be useful in making personnel decisions.

Besides the three interpersonal needs contained in the original FIRO-B, research includes an additional variable, warmth - the hybrid of adding inclusion and affection scores together. Wiedmann, Waxenberg and Mona $(1979,202)$ developed the warmth variable, and note there is a "significant correlation between rank-ordered performance and the combined 'inclusion' and 'affection' scores". Fisher, Macrossen, and Walker (1995) study warmth in software development teams and find it to be a significant variable that explains how individuals participate in a team setting. Therefore, the warmth variable is included in this study.

Straub and Carlson (1989) indicate that a main concern of any research using a survey instrument is ascertaining its validity. The FIRO-B instrument has been widely applied and validated. For example, Schutz (1966) uses the instrument in an educational community setting to study the interpersonal needs of 6,000 individuals. Doherty and Colangelo (1984) use it to help assess theories on family therapy. Schutz (1987) uses FIRO-B to assist in organizing the various ways individuals' make decisions; and Fisher, Macrossen, and Walker (1995) note the FIRO-B model is used in numerous professional fields.

In the accounting literature, Bayou, Siegel, and Smith (2006) apply FIRO-B to identify the interpersonal needs of CPAs in different cultures. In the business field, Thompson (1998, 116) indicates FIRO-B is used frequently for team-based analysis noting the FIRO-B allows insight into "individual interactions, team dynamics, team member compatibility, team development, team effectiveness, and team member satisfaction". The cost of testing, scoring and analysis of the FIRO-B instrument is nominal, and testing time is approximately 15 minutes.

\section{RESEARCH METHODOLOGY}

This study focuses on whether successful tax professionals demonstrate greater social interaction skills than non-tax accounting professionals. Using the FIRO-B instrument, it tests whether differences exist between tax and other accounting professionals using the following measures: SII Scores, Expressed Inclusion, Wanted Inclusion, Total Inclusion, Expressed Control, Wanted Control, Total Control, Expressed Affection, Wanted Affection, Total Affection, Expressed Warmth, Wanted Warmth, and Total Warmth. 


\section{Hypotheses}

There are 13 hypotheses used in this study. The basic underlying hypothesis is that there are no differences between tax and other accounting professionals:

- $\quad$ In SII Scores (H1),

- $\quad$ In Expressed Inclusion (H2),

- $\quad$ In Wanted Inclusion (H3),

- In Total Inclusion (H4),

- $\quad$ In Expressed Control (H5),

- In Wanted Control (H6),

- In Total Control (H7),

- $\quad$ In Expressed Affection (H8),

- In Wanted Affection (H9),

- In Total Affection (H10),

- $\quad$ In Expressed Warmth (H11),

- $\quad$ In Wanted Warmth (H12), and

- $\quad$ In Total Warmth (H13).

\section{Data Collection and Characteristics}

The data was collected at two separate points between 2003 and 2005. The survey instruments were sent to regional and national CPA firms within the United States. A coordinating representative at each firm distributed the instrument to various tax and non-tax accounting professionals for completion. The individual completing the survey then returned the instrument, anonymously, to the researchers. The instrument consisted of demographic data gathering (gender, education level, years of experience, and certified public accountant status), as well as the FIRO$\mathrm{B}$ questionnaire, which is included as Appendix A. There were no identifiable differences between the early and late participants nor were there any differences between the two separate collection groups. The respondents were then broken down into tax and non-tax categories based upon expertise and practice area.

Table 1: Respondents' Profile

\begin{tabular}{lcc}
\hline $\mathbf{n}$ & Tax & Non-Tax \\
Average Age & 89 & 107 \\
Male & 38.9 & 34.7 \\
Female & 50 & 51 \\
CPA & 39 & 56 \\
Non-CPA & 85 & 98 \\
Experience in Field (years) & 4 & 9 \\
Bachelor Degrees & 13 & 10.9 \\
Masters Degrees & 35 & 55 \\
Juris Doctorate/LL.M. & 32 & 52 \\
\hline
\end{tabular}

Table 1 presents the demographic data of the participants. There were a total of 196 viable responses. No differences in demographics and SII scores are identified between earlier and later respondents. Differences in demographics are nominal between groups. The tax group is slightly older, more experienced, and more likely to have a post baccalaureate degree. Schutz (1994) finds that FIRO-B scores are constant for individuals over long periods of time, and others have found consistency in personality scores as individual age (Costa and McCrae 1990). There are more males than females in the tax group, but no differences in FIRO-B scores exist between males and females. This finding is consistent with prior studies in other areas (Kube 1992; McRae and Young 1990). 


\section{RESULTS AND DISCUSSION}

Table 2 shows the results of the FIRO-B survey instrument between tax and other accounting professionals. The table presents the mean scores for (1) the total SII score, (2) the three interpersonal needs (inclusion, control and affection) and their expressed and wanted sub-categories, and (3) the warmth variable and its expressed and wanted subcategories. ANOVA tests were performed to determine whether significant differences exist between the scores of tax and non-tax professionals. The associated p-values are reported.

Table 2: FIRO-B Results for Testing the Hypotheses

\begin{tabular}{|c|c|c|c|}
\hline & $\begin{array}{c}\text { Tax } \\
\text { Professionals } \\
\end{array}$ & $\begin{array}{c}\text { Non-Tax } \\
\text { Professionals }\end{array}$ & p value \\
\hline SII (H1) & 27.31 & 25.49 & $.04 *$ \\
\hline \multicolumn{4}{|l|}{ Inclusion: } \\
\hline Expressed Inclusion (H2) & 4.78 & 4.77 & .977 \\
\hline Wanted Inclusion (H3) & 4.95 & 3.76 & $.04 *$ \\
\hline Total Inclusion (H4) & 9.73 & 8.53 & $.10^{* *}$ \\
\hline \multicolumn{4}{|l|}{ Control: } \\
\hline Expressed Control (H5) & 4.66 & 4.43 & .676 \\
\hline Wanted Control (H6) & 3.51 & 3.56 & .940 \\
\hline Total Control (H7) & 8.17 & 7.99 & .59 \\
\hline \multicolumn{4}{|l|}{ Affection: } \\
\hline Expressed Affection (H8) & 4.54 & 4.55 & .954 \\
\hline Wanted Affection (H9) & 4.87 & 4.42 & $.08 * *$ \\
\hline Total Affection (H10) & 9.41 & 8.97 & .294 \\
\hline \multicolumn{4}{|l|}{ Warmth: } \\
\hline Expressed Warmth (H11) & 9.32 & 9.32 & .948 \\
\hline Wanted Warmth (H12) & 9.82 & 8.18 & $.08 * *$ \\
\hline Total Warmth (H13) & 19.13 & 17.50 & $.10^{* *}$ \\
\hline
\end{tabular}

As can be seen in Table 2, $\mathrm{H} 1$ and $\mathrm{H} 3$ are rejected at the .05 level, and $\mathrm{H} 4, \mathrm{H} 9, \mathrm{H} 12$ and $\mathrm{H} 13$ are rejected at the .10 level. No significant differences were found for the other measures. The most important and significant finding is the SII score. This is the most important variable in the study because it represents the overall desire for interpersonal relationships (H1). At the .05 level, tax professionals scored higher (27.31) than the non-tax professionals (25.49) on this measure. These results provide evidence that tax professionals have a greater desire for social interaction than other accounting professionals.

Whetten and Cameron (1988) find general business professionals have an SII Score of 29.3. The tax professionals' average SII score is 27.31. This suggests that, as a group, the tax professionals have greater need for social interaction than non-tax accounting professionals, but less need than business professionals in general. Tax professionals are required to work at some non-team activities such as researching and compliance. At the same time, they are also involved in a number of interactive activities such as working with the external and internal auditors, planning tax strategies with clients, representing clients in front of the IRS, working with corporate tax departments, and working with attorneys and a wide variety of other professionals such as fiduciaries and trustees as well as a client's estate planning team.

Wanted inclusion (H3) is also significant at the .05 level. This shows tax professionals want to be included more than other accounting professionals, and they have a greater need for others to include them on the team. These results can help management. For example, they can use this information in the hiring process, in creating teams, and in determining when to include the staff in meetings. In addition, these results may assist educators in advising students and establishing tax-teaching methodologies. Hite (1996) already reports that, when working in groups, tax students perform better and enjoy the course more. The results for wanted inclusion in the present study, therefore, are consistent with Hite's findings. 
Total inclusion (H7) is significant at the .10 level. This suggests tax professionals have a need to include others, and a need to be included. However, total inclusion is the sum of both expressed and wanted inclusion. Table 2 shows the average expressed inclusion score for tax and other professionals is almost the same. Wanted inclusion is significantly higher for tax professionals at the .05 level, and expressed inclusion is not significant at all. Thus, wanted inclusion contributed most to the significance of total inclusion.

Total warmth (H13) and wanted warmth (H12) are both significant at the .10 level. The total warmth variable is explained as the adoption of common goals in a team setting (Fisher, Macrossen, and Walker 1995). Similar to total inclusion and wanted inclusion, total warmth seems to be influenced by the higher average score of tax professionals on wanted warmth. The scores of tax professional are significantly higher than those of other professionals studied. Fisher, Macrossen, and Walker (1995) indicate a correlation between higher total warmth scores and commercial performance. Thus, these results on the warmth variable are particularly interesting because of the potential economic consequences.

Wanted affection (H9) is the final significant variable. Thompson and Schutz (2000) show that individuals with higher wanted affection scores have positions that include strained relationships in the workplace. Since tax professionals are advocates for their clients, potential conflicts could result regarding a tax filing position or even something as small as advising a client that they owe additional taxes. Thus, tax professionals seem to compensate for this stress by seeking affection.

The results of this study are only applicable to CPA firms. However, future research on the social skill preferences of tax professionals in CPA firms might consider expanding the research to consider the following suggestions:

1. A majority of these accountants in this study got their start in public accounting. A good approach would be to study large corporate accounting departments where there are unique tax and non-tax accounting divisions to see if the results of this study apply to tax accountant in the corporate world.

2. The social interaction skills of tax and non-tax accounting students in Master-level accounting programs could be compared to whether there are any differences between the two groups. Accounting students could also be compared to their professional counterparts.

3. The MBTI in combination with the FIRO-B could be used to examine the social skills of tax professionals This methodology, a new approach, is being applied in non-business research and could be used to examine the social skills of tax professionals. This additional valuable information regarding the personality and social skills affecting the interpersonal relationships of the contrasted professionals in this study.

As shown by the demographics, the tax professionals in this study are successful and experienced. They show a higher need for social interaction preferences overall. In particular, they want to be included by others, desire common goals in a team setting, and want to be liked because it helps them deal with the strain of the professional/client relationship.

The growing globalization of the world economy presents challenge to the taxation field overall. Selecting the right individuals to meet these challenges require CPA firms and educators to better understand the requisite social interaction skills that individuals and firms require to meet the demands of an increasingly complex world.

\section{SUMMARY AND CONCLUSIONS}

This study examines tax professionals by using the FIRO-B instrument (Thompson and Schutz 2000) to compare their social interaction preferences to those of their non-tax accounting peers. The groundwork regarding FIRO-B and its applicability to accounting was laid out by Bayou, Siegel and Smith (2006), Siegel, Smith and Mosca (2001), Siegel and Smith (2003), and Whetten and Cameron (1998).

The FIRO-B instrument is employed to assess the social interaction preferences of tax professionals. The reason for choosing the FIRO-B instrument is to assess what behavioural factors are descriptive of tax professionals. The results suggest that tax professionals have a higher SII score than all other accounting professionals as a group 
and, thus, have a greater need for social interaction. For example, tax professionals have contact with a greater multitude of clients than other accounting professionals, and have the need to work and interact in a team setting. They work with and are advocates for their clients. On behalf of their clients, they work with lawyers and other types of professionals external to their firm.

The benefits of using the FIRO-B instrument far exceed the cost of its use. The cost is nominal while the cost of turnover can be significant. With the increasing demand for qualified tax professionals, educating, hiring and retaining these individuals is becoming more important.

Accounting firms, companies, and human resource departments can use these results to better place accountants in either the tax or non-tax groups, and to help firms create better internal practices for staffing, planning engagements, and retaining tax professionals. In addition, knowledge of these results may assist educators in counselling accounting students about whether tax is a field better suited to their talents and social traits.

\section{AUTHOR INFORMATION}

Michelle Bertolini is an assistant professor in accounting at University of Hartford. She has her LL.M. from Thomas Jefferson School of Law and her J.D. from Stetson University College of Law. She is also a CPA in Florida, Georgia and Wisconsin. Her research interests include behavioral tax issues, taxation of international transactions and insurance taxation issues. She has published a number of peer-reviewed journals.

Carl Borgia is an associate professor in accounting at Florida Atlantic University. He is a CPA in the State of Florida. His research interests include behavioral accounting issues and international accounting. He has published in a number of peer-reviewed journals. Last, Carl is an artist and has shown his works in New York and Florida.

Philip Siegel is distinguished chair in accounting at Augusta State University. Ph.D. in Accounting from the University of Memphis and is an active CPA in the state of Florida. His research interests are behavioral accounting and international accounting. He has published in the Journal of Accounting, Auditing and Finance; Journal of Business Ethics; Behavioral Research in Accounting; Advances in Accounting and other peer-reviewed and professional journals.

\section{REFERENCES}

1. Anonymous (2008a). The tax talent pool diminishes. International Tax Review, London: Apr 2008

2. Anonymous (2008b). Tax route to the top. International Tax Review, London: Mar 2008.

3. Anonymous (2008c). Reducing turnover costs become higher priority as economy slows. CPA Practice Management Forum, 4(2): 15.

4. Anonymous (2008d). Talent management. Partner's Report, 8(2): 7.

5. Ahadiat, N. and Smith, K.J. (1994). A factor-analytic investigation of employee selection factors of significance to recruiters of entry-level accountants. Issues in Accounting Education, 9(1): 59-79.

6. Bayou, M., Siegel, P. and Smith, J. (2006). Social skill differences among CPA firm personnel of different cultures: An exploratory study using the FIRO-B. International Journal of Business Research, 1(3): 15-25.

7. Costa, P.T. Jr. and McCrae, R.R. (1990). Personality disorders and the five-factor model of personality. Journal of Personality Disorders, 4: 362-371.

8. Cruz, C.A., Shafer, W. E. and Strawser, J. R. (2000). A multidimensional analysis of tax practitioner's ethical judgements. Journal of Business Ethics, 24(3): 223.

9. Dean, R. A., Ferris, K. R. and Konstans, C. (1988). Occupational reality shock and organizational commitment: Evidence from the accounting profession. Accounting, Organization and Society, 13: 235250 .

10. Fisher, S. G., Macrossen, W. and Walker, C. A. (1995). FIRO-B: The power of love and the love of power. Psychological Reports, 76: 195-206.

11. Hite, P.A. (1996). An experimental study of the effectiveness of group exams in an individual income tax class. Issues in Accounting Education, 11(1): 61. 
12. Jacoby, P. F. (1981). Psychological types and career success in the accounting profession. Research in Psychological Types, 4: 24-37.

13. Kahle, J.B. and White, R. A. (2004). Tax professional decision biases: The effect on initial beliefs and client preference. The Journal of the American Taxation Association, 26: 1.

14. Kleinman, G. and Palmon, D. (2000). Understanding Auditor-Client Relationships: A Multi-Faceted Analysis. Markus Weiner Publishers, Inc., Princeton, NJ.

15. Kubes, M. (1992). Cognitive style and interpersonal behavior: The Kirton Adaptation-Innovation and Schutz's FIRO-B inventories. Psychology-A Journal of Human Behavior, 29: 33-38.

16. Kuesel, A. and Ryan, R. (2008). Keepin' the ones you have. CPA Practice Management Forum, 4(12): 5-9.

17. Lasilla, D. R. and Smith, L. M. (1997). Tax complexity and compliance costs of U.S. multinational corporations. Advances in International Accounting, 10: 207.

18. McRae, L. and Young, J. (1990). Field independence and the FIRO-B. Perceptual and Motor Skills, 70: $493-494$.

19. Michaelsen, R. H. and Nichols, N. B. (1999). An examination of the psychological traits that affect the ability of tax experts to communicate their expertise. International Journal of Intelligent Systems in Accounting, Finance and Management, 8(3): 145.

20. Pasewark, W. R. and Strawser, J. R. (1996). Determinants and outcomes associated with job insecurity in a professional accounting environment. Behavioral Research in Accounting, 8: 91-113.

21. Pozanski, P. J. and Bline, D. M. (1997). Using structural equation modeling to investigate the casual ordering of job satisfaction and organizational commitment among staff accountants. Behavioral Research in Accounting, 9: 154-171.

22. Satava, D. (1996). Personality types of CPAs: National versus local firms. Journal of Psychological Type, 36: $36-41$.

23. Scarborough, D. P. (1993). Personality types and job satisfaction of accountants. Journal of Psychological Type, 25: 3-10.

24. Schloemer, P. G. and Schloemer, M. S. (1997). The personality types and preferences of CPA firm professionals: An analysis of changes in the profession. Accounting Horizons, 11(4): 24-39.

25. Schutz, W. C. (1958). FIRO: A Three Dimensional Theory of Interpersonal Behavior: Holt, Rinehart and Winston, New York, NY.

26. Schutz, W. C. (1966). The FIRO Scales Manual: Consulting Psychologists Press, Palo Alto, CA.

27. Schutz, W. C. (1987). Concordance: Decision Making: WAS, Mill Valley, CA.

28. Schutz, W. C. (1992). Beyond FIRO-B: Three new theory derived measures-Element B: Behavior, Element F: Feelings, Element S: Self. Psychological Reports, 70: 915-937.

29. Schutz, W. C. (1994). The Human Element: Productivity, Self-Esteem and the Bottom Line: Jossey-Bass, San Francisco, CA.

30. Sheridan, J. E. (1992). Organizational culture and employee retention. The Academy of Management Journal, 35(5): 1036-1056.

31. Siegel, P. H., Smith, J. W. and Mosca, J. B. (2001). Mentoring relationships and interpersonal orientation. The Leadership \& Organizational Development Journal, 22(3): 114-126.

32. Siegel, P. H. and Smith, J. W. (2003). Beyond FIRO-B: An Examination Using the FIRO-B. Journal for Business and Entrepreneurship, 15(2): 77-96.

33. Steadman, M. (2008). What small CPA firms are during to recruit and retain staff. The CPA Journal 78(7): 61.

34. Straub D. W. and Carlson, C. L. (1989). Validating instruments in MIS research. MIS Quarterly. 13 (2).

35. Thompson, H. (1998). Using the FIRO-B and MBTI. Management \& Organization Development, 4: 18-20.

36. Thompson, H. and Schutz, W. (2000). FIRO Element B Organizational Interpretive Report: High Performing Systems, Inc., Watkinsville, GA.

37. Viator, R. E. (2001). The association of formal and informal public accounting mentoring with role stress and related job outcomes. Accounting, Organizations and Society 26: 73-93.

38. Wheeler, P. (2001). The Myers-Briggs Type Indicator and applications to accounting education and research. Issues in Accounting Education 16(1): 125-150.

39. Whetten, D. and Cameron, K. (1988). Developing Management Skills: Scott, Foresman and Company, Glenview, IL.

40. Wiedemann, C., Waxenberg, S. and Mona, L. C. (1979). Factor Analysis of FIRO-B and FIRO-F. Small Group Research, 10: 49-61. 


\section{APPENDIX A}

\section{Fundamental Interpersonal Relations Orientation-Behavior (FIRO-B)}

(Thompson and Schutz 2000)

For each statement below, decide which of the following answers best applies to you:
1. Usually
2. Often
3. Sometimes
4. Occasionally
5. Rarely
6. Never

I try to be with people.

I let other people decide what to do.

I join social groups.

I try to have close relationships with people.

I tend to join social organizations when I have an opportunity.

I let other people strongly influence my actions.

I try to be included in informal social activities.

I try to have close, personal relationships with people.

I try to include other people in my plans.

I let other people control my actions.

I try to have people around me.

I try to get close and personal with people.

When people are doing things together I tend to join them.

I am easily led by people.

I try to avoid being alone.

I try to participate in group activities.

For each of the next group of statements, choose one of the following answers:
1. Most
2. Many
3. Some
4. A few
5. One or two
6. Nobody
people
people
people
people
people

I try to be friendly to people.

I let other people decide what to do.

My personal relations with people are cool and distant.

I let other people take charge of things.

I try to have close relationships with people.

I let other people strongly influence my actions.

I try to get close and personal with people.

I let other people control my actions.

I act cool and distant with people.

I am easily led by people.

I try to have close, personal relationships with people. 
For each of the next group of statements, choose one of the following answers:
1. Most 2. Many
people people
3. Some
4. A few people
5. One or two people
6. Nobody

I like people to invite me to things.

I like people to act close and personal with me.

I try to influence strongly other people's actions.

I like people to invite me to join in their activities.

I like people to act close toward me.

I try to take charge of things when I am with people.

I like people to include me in their activities.

I like people to act cool and distant toward me.

I try to have other people do things the way I want them done.

I like people to ask me to participate in their discussions.

I like people to act friendly toward me.

I like people to invite me to participate in their activities.

I like people to act distant toward me.

For each of the next group of statements, choose one of the following answers:

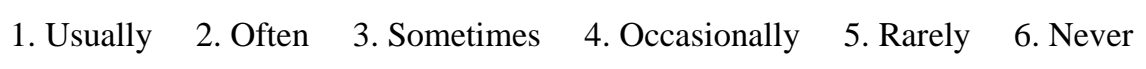

I try to be a dominant person when I am with people.

I like people to invite me to things.

I like people to act close toward me.

I try to have other people do things I want done.

I like people to invite me to join their activities.

I like people to act cool and distant toward me.

I try to influence strongly other people's actions.

I like people to include me in their activities.

I like people to act close and personal with me.

I try to take charge of things when I'm with people.

I like people to invite me to participate in their activities.

I like people to act distant toward me.

I try to have other people do things the way I want them done.

I take charge of things when I'm with people. 